\title{
Investigation of Micro Defect on the Shear Crack Growth Properties Using FRANC2D
}

\author{
V. Sarfarazi ${ }^{1}$ and Hadi Haeri ${ }^{2, *}$ \\ ${ }^{1}$ Department of Mining Engineering, Hamedan University of Technology, Hamedan, Iran \\ ${ }^{2}$ Postdoctoral fellow in Civil Engineering, Department of Civil Engineering, Sharif University of \\ Technology, Member of National Elites Foundatison, Tehran, Iran \\ *Corresponding author: haerihadi@gmail.com
}

Keyword: Micro pore, crack growth properties, FRANC2D

\begin{abstract}
In this article the non-linear finite element method is used to analyze the effect of presence of micro pore near a crack tip on both of the characteristics of crack tip plastic zone (its shape and size) and crack growth properties (such as crack growth length and crack initiation angle) under pure shear loading. The FE Code Franc2D/L is used to carry out these objectives. The effects of the crack-pore configurations and the spacing between micro pore and pre-excising crack tip on the characteristics of crack tip plastic zone and crack growth properties is highlighted. Based on the obtained results, the relative distance between the crack tip and the micro pore affects in very significant way the shape and the size of the crack tip plastic zone. Furthermore, crack growth length and crack initiation angle are mostly influenced by size and shape of plastic zone ahead of crack tip. Also the effects of pore decrease on the crack tip by variation of pore situation from linear to perpendicular configuration. The critical position for a micro pore is in front of the crack tip.
\end{abstract}

\section{Introduction}

It is well known that rock is a heterogeneous geological material containing many natural weaknesses, such as micro cracks, pores and grain boundaries. Under internal or external pressures, these preexisting defects can induce macro crack, which can in turn change the structure of the rock (Wang and Kemeny, [1]).

Also, Presence of natural weaknesses around the crack tip could change the stress distribution around the crack tip and lead to variations of characteristics of crack tip plastic zone such as plastic zone size and plastic zone shape. Such micro defects affect the fracture toughness and extension or kinking of the macro crack.

A study of the characteristics of crack tip plastic zone (such as plastic zone size and plastic zone shape) and crack grow properties (such as crack initiation stress, crack growth length, crack initiation angle and crack growth rate) with presence of crack-pore is important in providing a good understanding of failure behavior of rocks and is helpful to the rock structural design.

Theoretically, linear elastic stress analysis of cracks predicts infinite stresses at the crack tip. In fact, inelastic deformation, such as plasticity in ductile and brittle materials, leads to relaxation of crack tip stresses caused by the yielding phenomenon at the crack tip.

Most rock materials develop plastic strains when the yield strength is exceeded in the region near a crack tip. Thus, the amount of plastic deformation is restricted by the surrounding material, which remains elastic during loading. The formation of the plastic zone in a homogeneous material depends on the material properties, structural element configuration, and loading conditions. The size of the plastic zone can be estimated when moderate crack tip yielding occurs. 
The plastic behavior near the crack tip in engineering materials has been intensively studied using classical plasticity theory based on the Von-Mises yield criterion and the associative flow rules (Rice, [2]; Kuang, [3]).

The elastic interaction problem between a crack and micro defects in homogeneous solids has been well studied in recent years and a number of analytical solutions have been presented in the literature (see, e.g., Rose, [4]; Rubinstein, [5]; Horii and Nemat-Nasser, [6]; Grenon and Hadjigeorgiou, [7]; Gischig et al., [8]; Haeri, [9-10]; Haeri [11-12]; Gao et al., [13]).

When cracks are analyzed, the behavior of the material ahead of the crack tip is considered isotropic, i.e., plastic deformation occurs identically in all directions and there are no preferred directions for the plastic deformation. In this case, the plastic deformation can be mathematically formulated with the help of classical isotropic plasticity. This situation significantly differs when the crack tip is near a micro-defect; the plastic zone ahead of the crack tip will be affected by the presence of the microdefects.

The aim of this study is to analyze the effect of presence of micro-crack on the shape/size of the crack tip plastic zone and crack growth properties under pure shear loading using the finite element method for the case of small scale plasticity. This case was selected because a micro-pore cannot affect the plastic zone in large plastic deformation.

\section{Geometrical and Materials Models}

The model with height $\mathrm{H}$ and width $\mathrm{W}$, the ratio $\mathrm{W} / \mathrm{H}$ is equal to 1.0 , is subjected shear loading with amplitudes of $40 \mathrm{MPa}$.

An interface crack with length 'a' exists at the model. The ratio a/W is $1 / 30$. A circular micro pore with radius $r=400 \mu \mathrm{m}$ exist near the crack tip. The distance between the crack tip and the micro pore is b. The ratio b/a was taken equal to $10 \%, 15 \%, 20 \%$ and $25 \%$ in order to analyze the effect of the distance $b$ on the size and the shape of the plastic zone ahead of the crack tip. Three configurations of the position of the micro pore compared to the crack tip are studied:

(a) Micro pore located at the prolongation of the crack tip.

(b) Micro pore located diagonally below the crack tip. The angel between pore-crack connecting line and crack plane is $45^{\circ}$.

(c) Micro pore shifted perpendicularly below the crack tip.

The elastic properties of the model material are like to mechanical properties of marble. The Young modulus $\mathrm{E}=75.31 \mathrm{GPa}$, Poisson's ratio $(v)=0.32$ and yield stress $\left(\sigma_{\mathrm{yx}}\right)=75 \mathrm{MPa}$. The uniaxial stressstrain curve of this material is given in.

\section{Finite Element Modeling}

A two-dimensional finite element code named FRANC2D/L (FRacture ANalysis Code for 2-D Layered structures) is used to do the numerical modeling work. This code was originally developed at Cornell University and modified for multi-layers at Kansas State University (FRANC2D/L, [14]), and is based on the theory of linear and nonlinear elastic fracture mechanics (Newman; [15] ). FRANC2D/L has been developed based on fracture mechanic theory and has a good efficiency to analyze the crack growth properties.

The structure is idealized by quadrilateral four nodes element. Special quarter elements are implemented around the crack tip. The Von-Mises criterion is used to determine whether the stress in the material causes plastic flow. This criterion is chosen because, in addition to the well applicability in fracture mechanic theory, is an ideal criterion for this assumption that rock segment behaves as a metal material. In other words, Whereas on of the important source that cause the large differences between 
mechanical properties of rock material and metal are grain boundaries, porosity areas and other defects in rocks, therefore in this study it's assumed that there are just one crack and micro pore without any defects (such as grains boundary, dislocation) in rock segment. In this condition the rock mechanical behavior is nearly similar to metals behavior what confirm that the von-mises criterion can be applied in this study.

Incremental plasticity theory is introduced to model the material non-linearity. The NewtonRaphson iterative method is used as approach for resolving non-linear finite element equations.

\section{Analysis and Results}

The contour of the plastic zone at the crack tip with micro pore is compared to the case of without micro pore. It can be noted in all results presented in this paper that when the effect of micro-crack is non-existent the plastic zone at the crack tip has a regular form which is in accordance with literature (Anderson, [16]). In what follows, the effect of the presence of micro-pore near the crack tip on the size and the shape of the plastic zone is analyzed for the three configurations of the positions of the micropore shown previously.

Fig 1a present the contour of the Von-Mises stress levels near the crack tip without micro pore. As can be seen, the stress intensity at the crack tip has the maximum value of $80.76 \mathrm{MPa}$. In this condition, the new crack initiate from the crack tip (Fig 1b). The crack growth length is $100 \mu \mathrm{m}$ and the angle between newborn crack and pre-existing joint is about $73^{\circ}$.

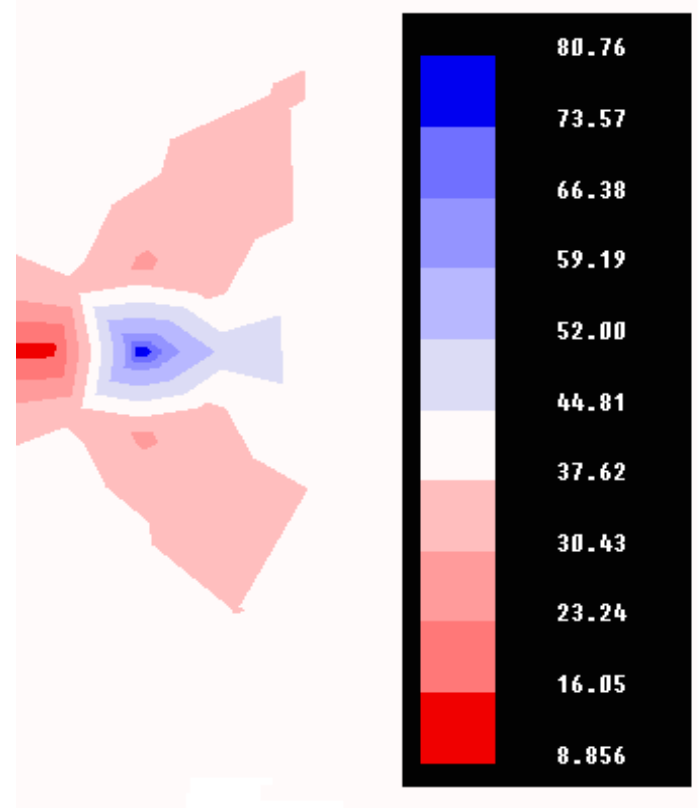

(a)

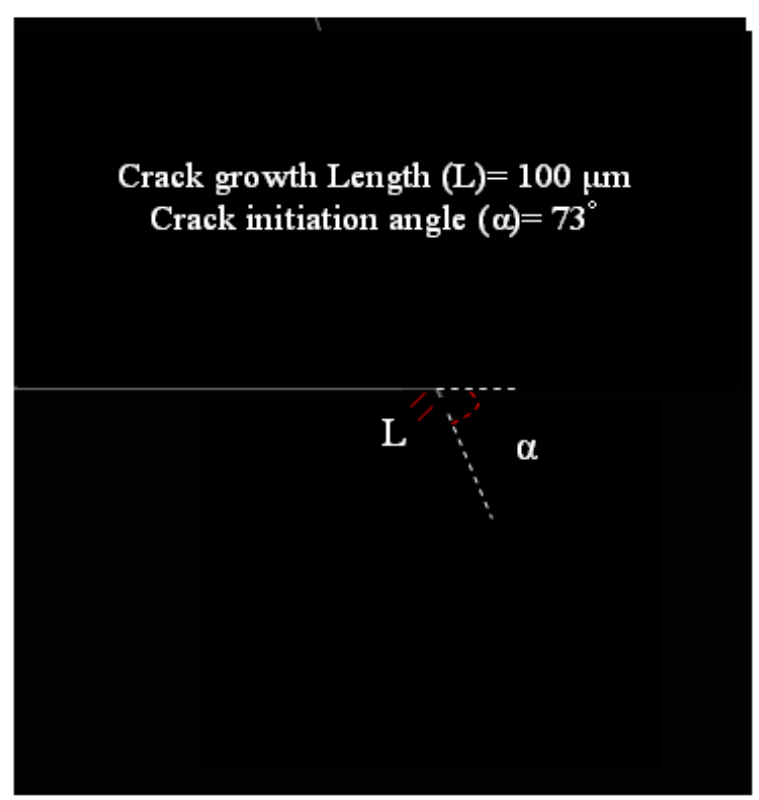

(b)

Fig 1.a) the contour of Von-Mises stress levels near the crack tip; b: crack growth properties.

\section{I) the ratio of $b / a=10 \%$ :}

Figs. 2a, 2b and 2c present the contour of the Von-Mises stress levels near the crack tip for configurations a, b and c in Fig 1 respectively (b/a=10\%).

From Fig 2 and Fig 1.a, it can be seen that the crack tip stresses are higher than $80.76 \mathrm{MPa}$ due to presence of micro pore and its interaction effects. The stress concentration the crack tip is highest for linear pore configurations (185.5 MPa). It decrease at the crack tip (185.5 MPa to 167.8 $\mathrm{MPa}$ ) when 
micro defect is shifted diagonally to the line of the crack. The stress concentration at the crack tip is less than other cases for perpendicularly micro pores (143 MPa). In fact the interaction effect between pore-crack stresses field decrease by movement of pore below the crack tip.

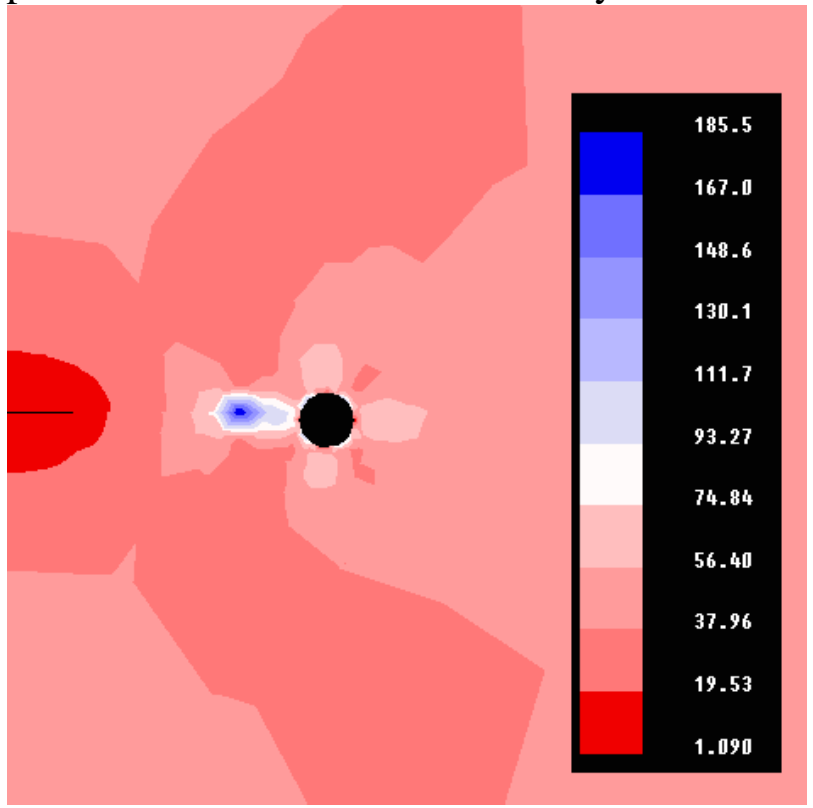

(a)

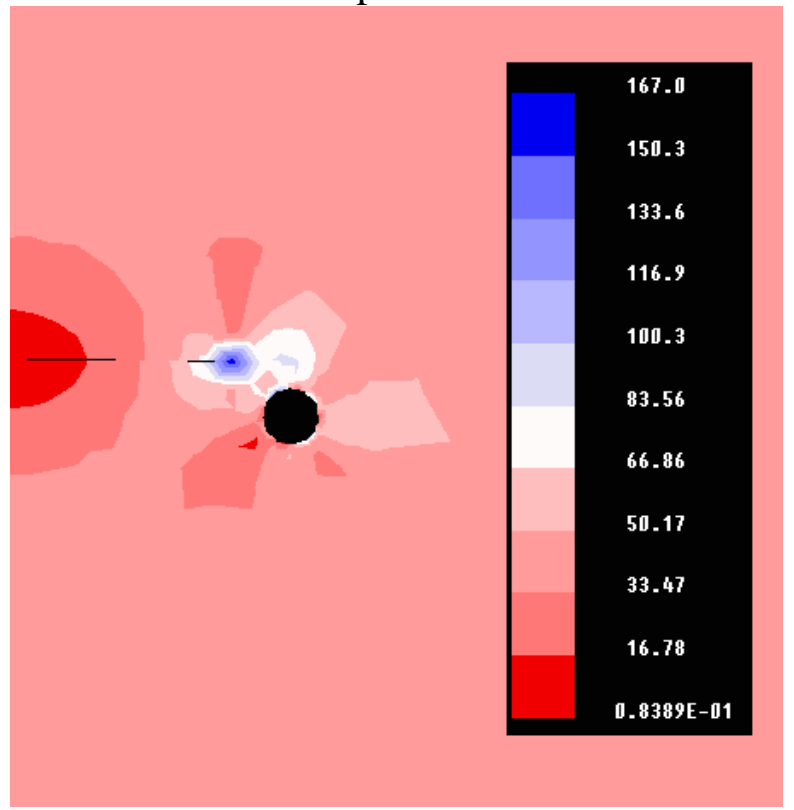

(b)

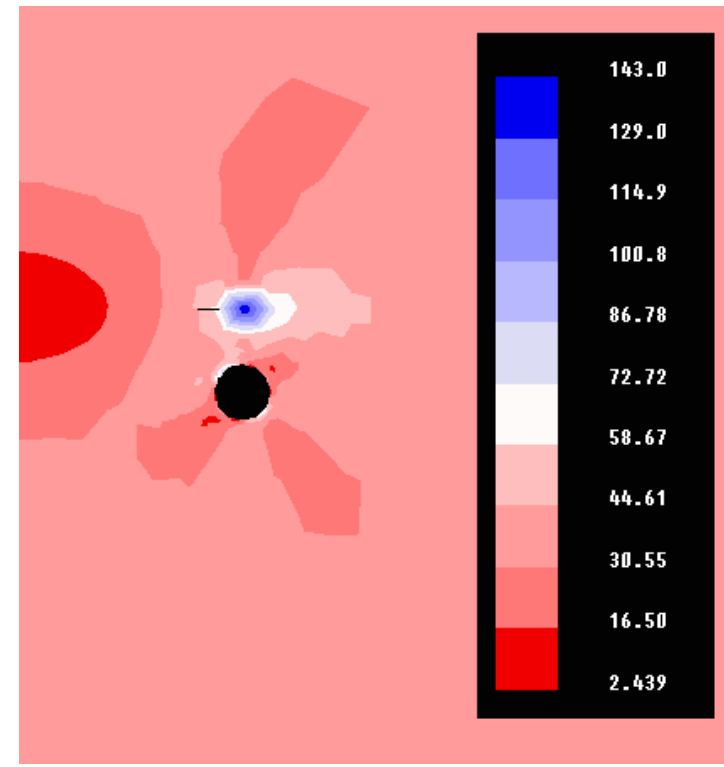

(c)

Fig. 2 Contour of Von-Mises stress levels near the crack tip ( $\mathrm{b} / \mathrm{a}=10 \%$ ); a) Micro pore located at the prolongation of the crack tip; b) micro pores located diagonally below the crack tip; c) Micro pore located below the crack tip.

Figs. 3a, 3b and 3c, shows the crack growth properties for three pore configurations ( $\mathrm{b} / \mathrm{a}=10 \%)$. When pore exist in front of the crack tip, the new born crack propagates at the prolongation of preexisting crack till reach the pore surface. The crack growth length is $400 \mu \mathrm{m}$ and the angle between newborn crack and the pre-existing crack is about $0^{\circ}$ (Fig 3a). 
When pore shifted diagonally to the line of the crack, the crack growth length is $400 \mu \mathrm{m}$ and the angle between newborn crack and the pre-existing crack is about $45^{\circ}$. It's to be note that, however the stress decrease at the crack tip for diagonally micro pore configuration (from 185.5 MPa to 167.8 MPa) but the interaction effect between pore-crack is too high and crack tip stress is too enough so that new born crack propagate till reach to the pore level. Also presence of diagonally micro pore changes the principal stress direction so that the crack growth angle increases to $45^{\circ}$.

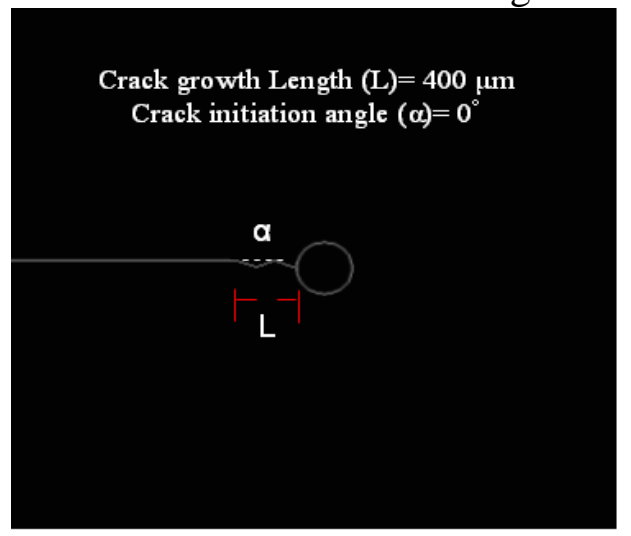

(a)

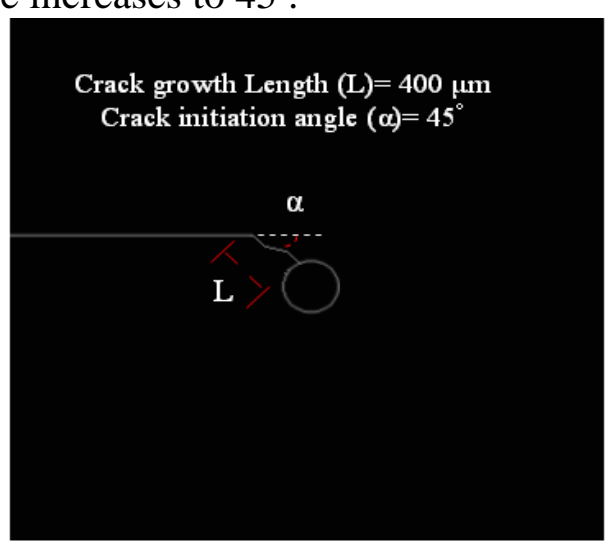

(b)

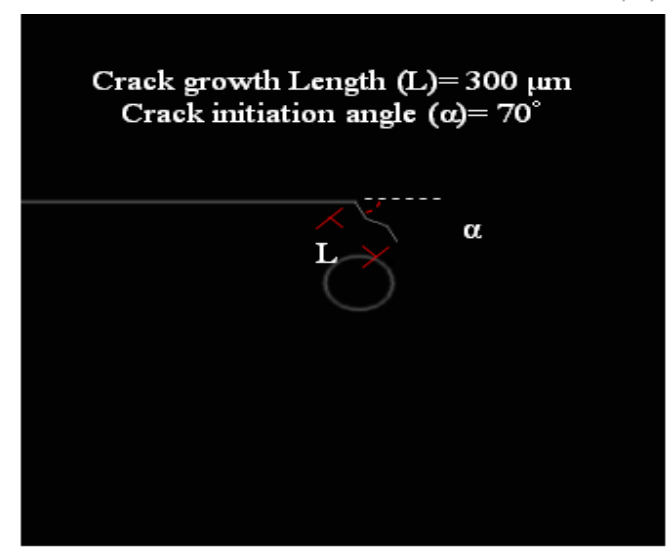

(c)

Fig. 3. Crack growth properties (b/a=10\%); a) Micro pore located at the prolongation of the crack tip; b) micro pores located diagonally below the crack tip; c) Micro pore located below the crack tip.

When pore shifted perpendicularly to the line of the crack (Fig, 3.c), the crack growth length is 300 $\mu \mathrm{m}$ and the angle between newborn crack and the pre-existing crack is about $70^{\circ}$. In contrast with other configuration, the crack growth length is smallest one. In fact in this configuration, the interaction between pore-crack stresses field is less than other configurations so that it reduce the crack tip stress and crack growth length. From Fig 3 and Fig 1, it can be found that presence of micro pore can lead to increasing in the crack growth length and decreasing in crack initiation angle. In fact, presence of micro pore in the vicinity of the crack tip leads to the high interaction between the crack-pore stress fields what causes increasing in the energy at the crack tip and consequently increasing the crack growth length. Also, presence of micro pore linearly and diagonally at the crack tip change the principal stress direction what explain decreasing of crack initiation angle. It's to be note that variation of crack initiation angle can change crack propagation path. From Fig 3.c its worth noting that presence of perpendicularly micro pore has not any effect on the principal stress directions so that crack initiation 
angle with presence of perpendicularly pore configuration ( $70^{\circ}$ in Fig 3.c) is the same as that without of presence of pore $\left(73^{\circ}\right.$ in Fig 1.b).

\section{II) The ratio of $b / a=15 \%$ :}

Figs. 4.a, 4.b and 4.c present the contour of the Von-Mises stress levels near the crack tip for configurations $\mathrm{a}, \mathrm{b}$ and $\mathrm{c}$ in Fig 1 respectively ( $\mathrm{b} / \mathrm{a}=15 \%)$. It's clear that the stress concentration at the crack tip is highest for linear pore configuration (170.9 MPa). It decrease at the crack tip (170.9 MPa to 156.2 $\mathrm{MPa}$ ) when micro defect is shifted diagonally to the line of the crack. When micro pore is located perpendicularly to the line of crack the stress concentration at the crack tip is less than other cases $(122.7 \mathrm{MPa})$. From Fig 4 and Fig 2, it can be seen that the crack tip stress decrease by increasing in micro pore spacing. Also, from Fig 4 and Fig 1a, the crack tip stress with presence of pore is more that that without presence of pore. It shows that the micro pore has effect on the crack tip stress yet.

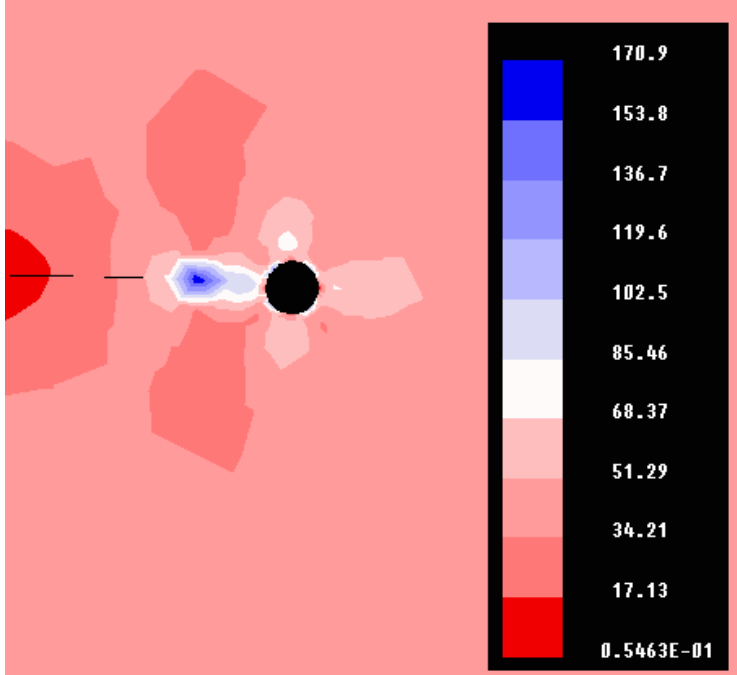

(a)

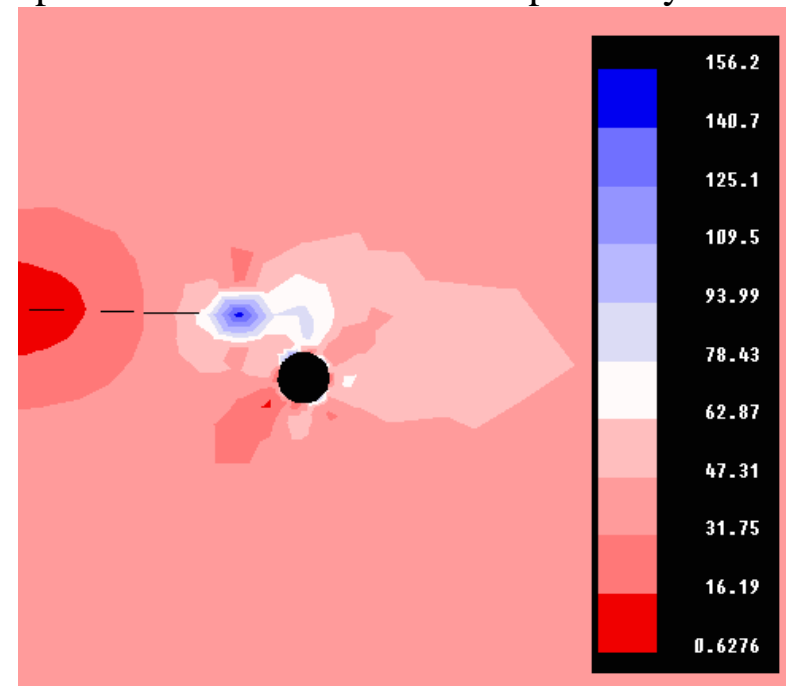

(b)

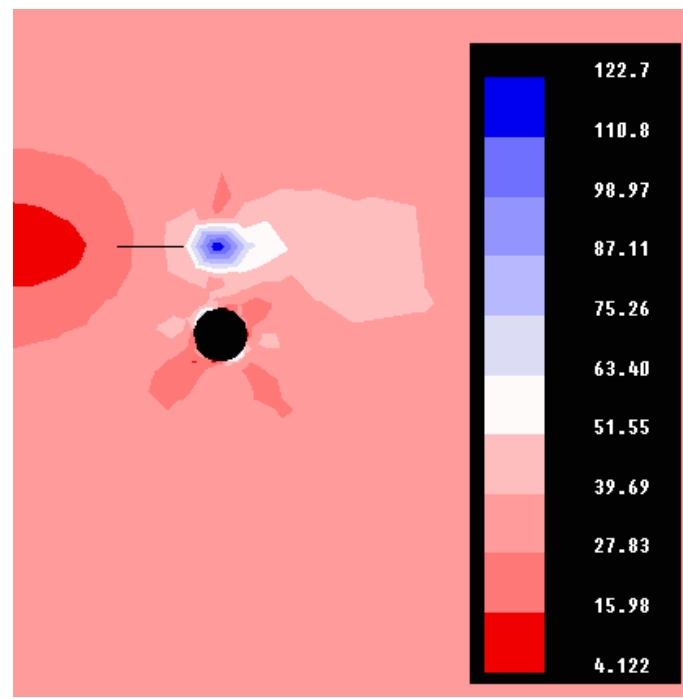

(c)

Fig. 4. Contour of Von-Mises stress levels near the crack tip (b/a=15\%); a) Micro pore located at the prolongation of the crack tip; b) micro pores located diagonally below the crack tip; c) Micro pore located below the crack tip. 
Fig 5.a, 5.b and 5.c, shows the crack growth properties for three pore configuration (b/a=15\%).

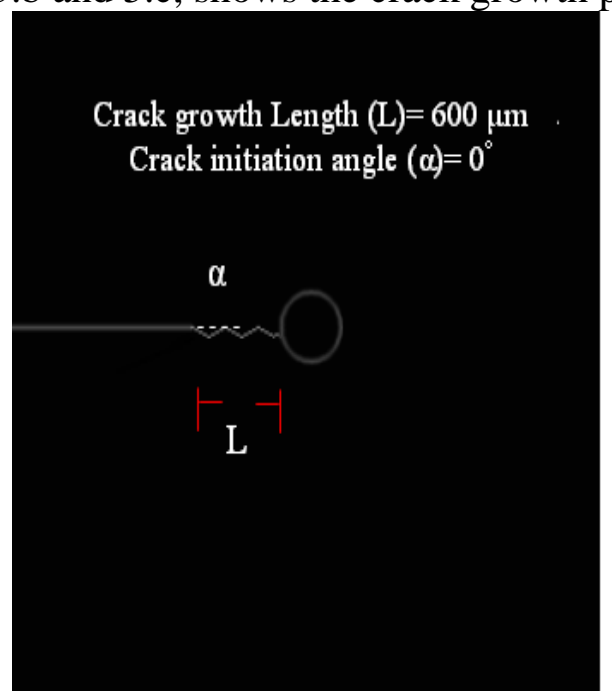

(a)

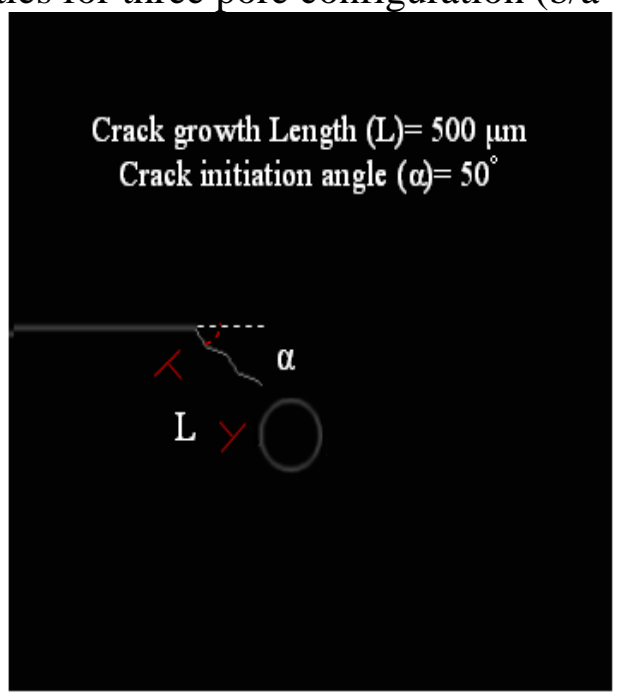

(b)

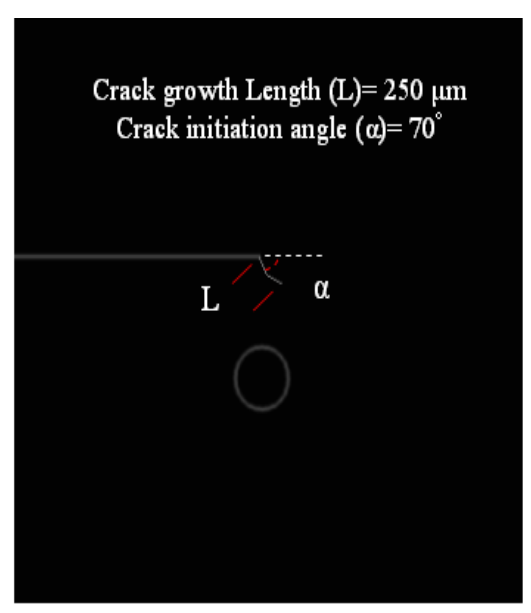

(c)

Fig. 5. Crack growth properties (b/a=15\%); a) Micro pore located at the prolongation of the crack tip; b) micro pores located diagonally below the crack tip; c) Micro pore located below the crack tip.

It's clear that for linear pore configuration the crack propagates parallel to pre existing crack till reach the pore level (the angle between newborn crack and the pre-existing crack is about $0^{\circ}$ ). The crack growth length is highest $(600 \mu \mathrm{m})$ because the crack tip stress is highest in this configuration (Fig 5.a). crack initiation grow angle increase $\left(0^{\circ}\right.$ to $\left.50^{\circ}\right)$ when micro defect is shifted diagonally to the line of the crack (Fig 5.b) and its growth length decrease $(600 \mu \mathrm{m}$ to $500 \mu \mathrm{m})$ due to reduction in crack tip stress (see Fig 4.a and Fig 4.b). When micro pore is located perpendicularly to the line of crack, the crack growth length is less than other cases $(250 \mu \mathrm{m})$ and the angle between newborn crack and the pre-existing crack is about $70^{\circ}$ (Fig 5.c). It worth nothing that however the crack tip stresses in linear and diagonally pore configurations, (170.9 MPa in Fig 4.a and 156.2 MPa in Fig 5.b) are less than those in similar preceding configurations (185.5 MPa in Fig 4.a and 167.8 MPa in Fig 5.b) but the crack growth lengths for $\mathrm{a} / \mathrm{b}=15 \%(600 \mu \mathrm{m}$ and $500 \mu \mathrm{m}$ in Figs 5.a and 5.b) are more than those for $\mathrm{b} / \mathrm{a}=10 \%(400 \mu \mathrm{m}$ in Figs. 3.a and 3.b). In fact for $\mathrm{b} / \mathrm{a}=10 \%$, the crack growth is arrested due to connecting with micro pore. When the crack tip reach to pore level, the sharp crack tip change to 
circular shape and stress is distributed in the pore surface (that is now a partial of crack). This leads to decreasing the energy at the crack tip and arresting the crack. This crack can propagate by further far field shear loading But when $\mathrm{b} / \mathrm{a}=15 \%$, for two introduced configuration, the crack tip stress is high enough to propagate further than preceding cases.

\section{III) The ratio of $b / a=20 \%$ :}

Figs. 6.a, 6.b and 6.c present the contour of the Von-Mises stress levels near the crack tip for configurations a, b and c in Fig 1 respectively (b/a=20\%). From Fig 6 and Fig 4, it can be seen that the crack tip stress decrease by increasing in micro pore spacing.

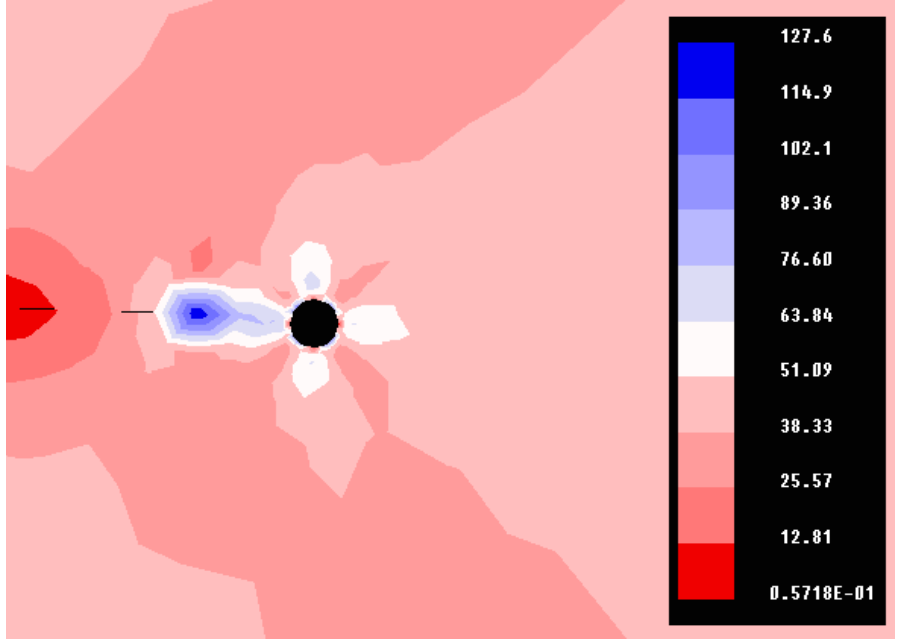

(a)

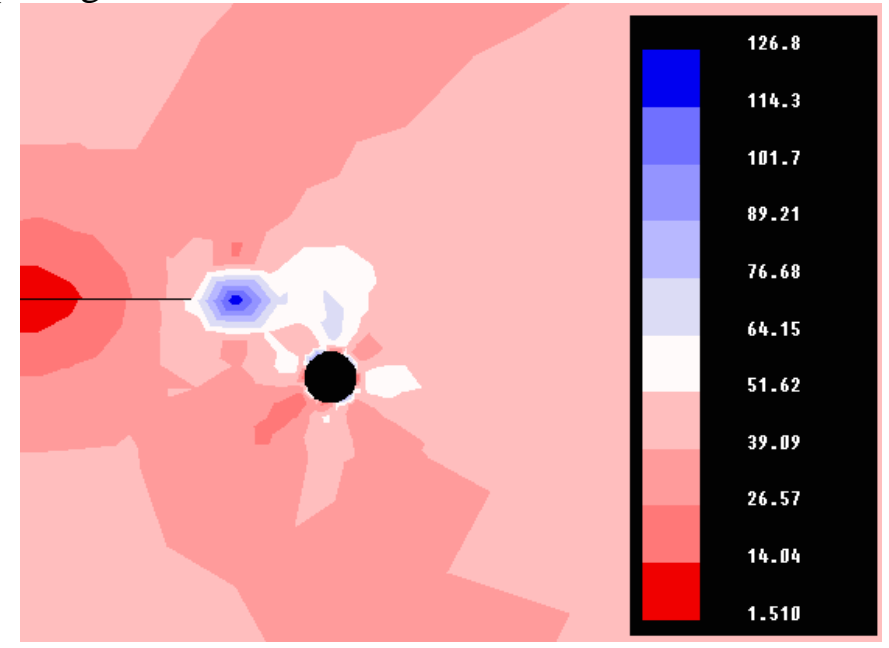

(b)

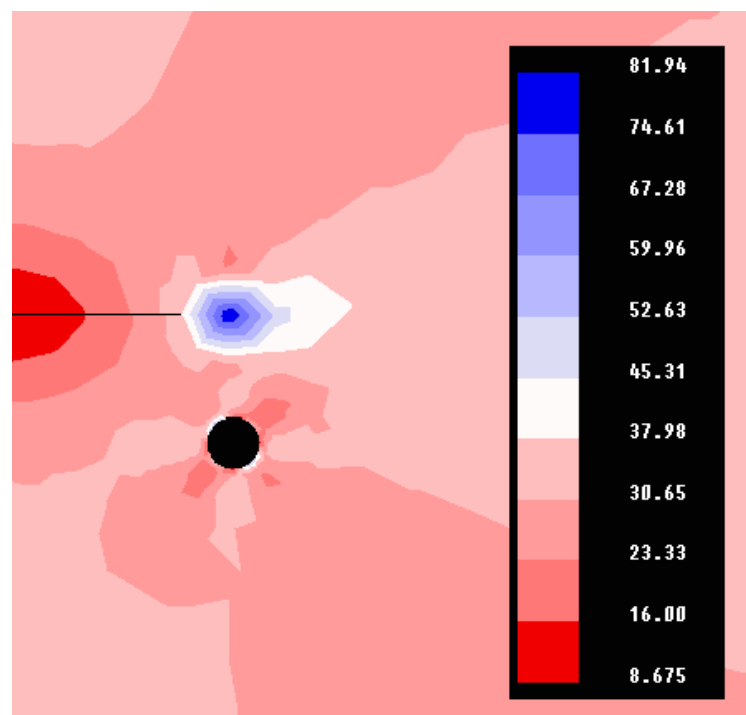

(c)

Fig. 6. Contour of Von-Mises stress levels near the crack tip (b/a=20\%); a) Micro pore located at the prolongation of the crack tip; b) micro pores located diagonally below the crack tip; c) Micro pore located below the crack tip.

The crack tip stresses for planar and diagonally pores configurations are nearly equal to each other (127.6 MPa and 126.8 MPa, respectively). It may be related to this fact that the crack tip, in these two configurations, has been situated in the disturbed zones of micro pores but not in the hazard zone (with 
high interaction effect). Whereas there is not any high interaction between crack tip and micro pore stress fields in disturbed zone therefore the same stresses concentrate at crack tip for planar and diagonally pores configurations.

When a micro pore is located perpendicularly to the line of crack, the stress concentration at the crack tip is less than other cases (81.94 MPa). In this case the pore has not any effect on the crack tip stress so that the crack tip stress is similar to case of without present of micro pore (Fig. 1.a).

Fig 7.a, 7.b and 7c, shows the crack growth properties for three pore configuration (b/a=20\%). When micro pore is sited in front of the crack tip, the crack growth length is $250 \mu \mathrm{m}$ and the angle between newborn crack and the pre-existing crack is about $50^{\circ}$. From Fig 6.a and Fig 4.a it's clear that when micro pore is far from the crack tip, the crack growth length decrease and crack growth angle increase due to reduction in pore effect.

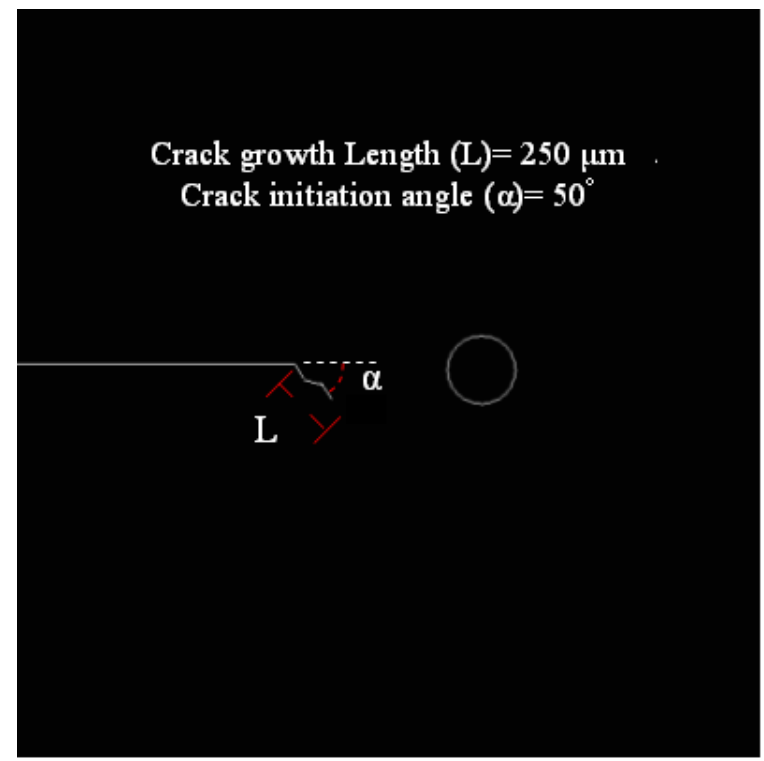

(a)

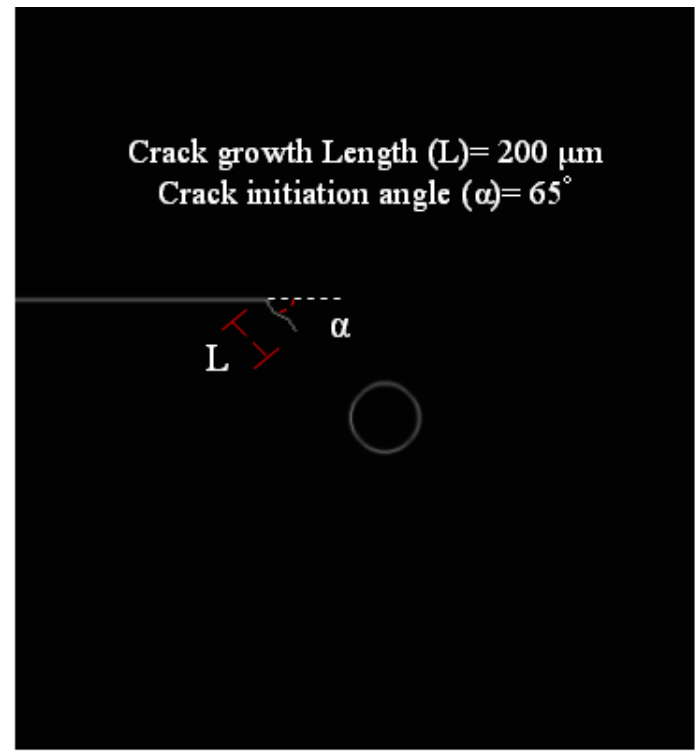

(b)

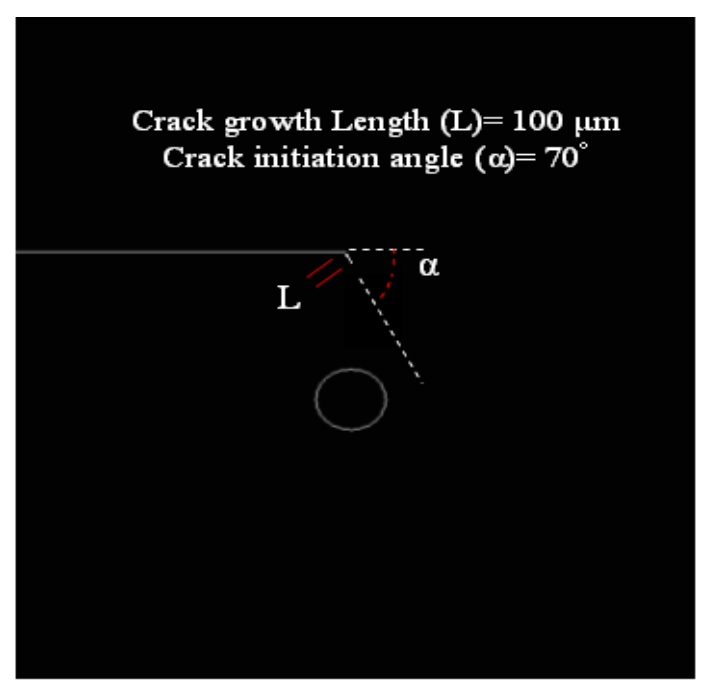

(c)

Fig. 7. Crack growth properties ( $\mathrm{b} / \mathrm{a}=20 \%)$; $\mathrm{a})$ Micro pore located at the prolongation of the crack tip; b) micro pores located diagonally below the crack tip; c) Micro pore located below the crack tip. 
When micro pore is shifted diagonally to the tip of crack, the crack growth length is $200 \mu \mathrm{m}$ and the angle between newborn crack and the pre-existing crack is about $65^{\circ}$.

Finally for perpendicularly pore configuration, the crack growth length and crack initiation angle is similar to standard form (Fig. 1) what explain the fact that micro pore has not any effect on the crack growth properties in this configuration/situation of micro pore.

\section{IV) The ratio of $b / a=25 \%$ :}

Figs. 8.a, 8.b present the contour of the Von-Mises stress levels near the crack tip for linear and diagonally pore configurations respectively (b/a=25\%).

The crack tip stresses for linear and diagonally pore configurations are 82.12 MPa and 81.94 MPa, respectively what's the same as standard value (i.e. $80.76 \mathrm{MPa}$ in Fig 1.a). It can be concluded that the effect of micro pore disappears completely in these configurations.

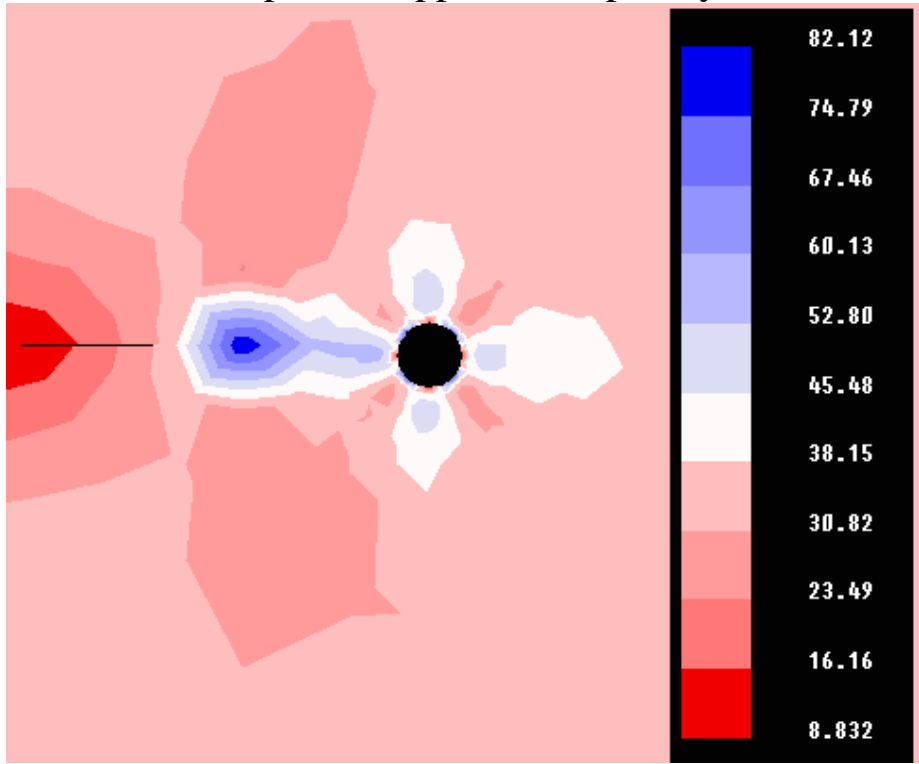

(a)

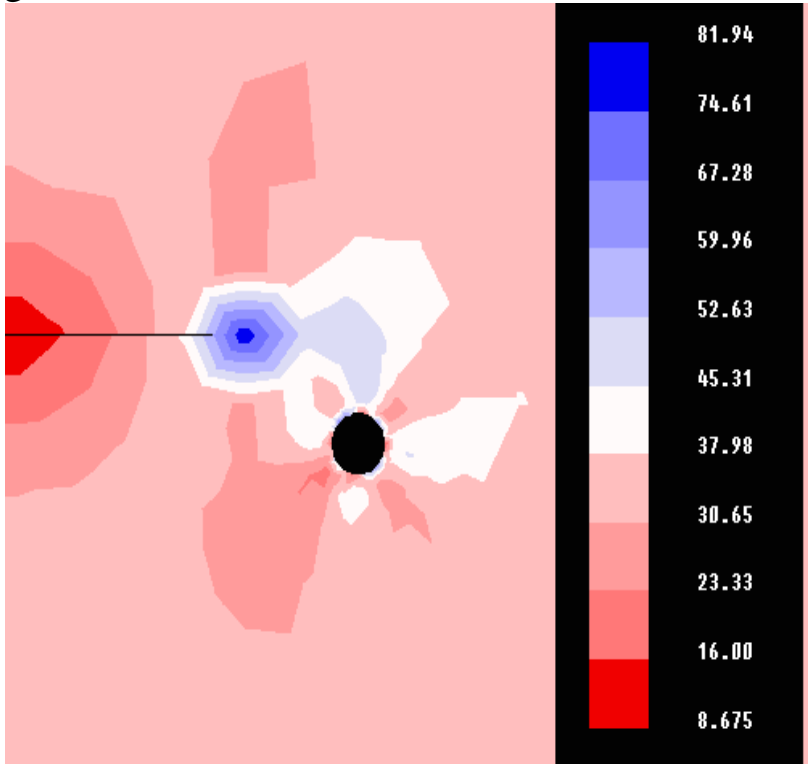

(b)

Fig. 8 Contour of Von-Mises stress levels near the crack tip (b/a=25\%); a) Micro pore located at the prolongation of the crack tip; b) micro pores located diagonally below the crack tip.

Also, Fig 9.a and 9.b, shows the crack growth properties for two pore configuration (b/a=25\%). its clear that the crack growth properties (crack growth lengths and crack initiation angles) are similar to standard form (Fig. 1.b) what explain the fact that micro pore has not any effect on the crack growth properties in these pore configurations.

From above findings, it's clear that the variation of pore situation from linear to perpendicular configuration lead to decreasing in crack tip stress and crack growth length. In other word, its effect decrease on the crack tip stress. This manner is unchangeable till b/a get the value of $25 \%$.

Also, for linear and diagonal pore configuration, the crack initiation angle increase by pore spacing till get the standard value $\left(73^{\circ}\right)$ but for perpendicular pore configuration the crack initiation angle will be constant by pore spacing and is similar to standard value. 


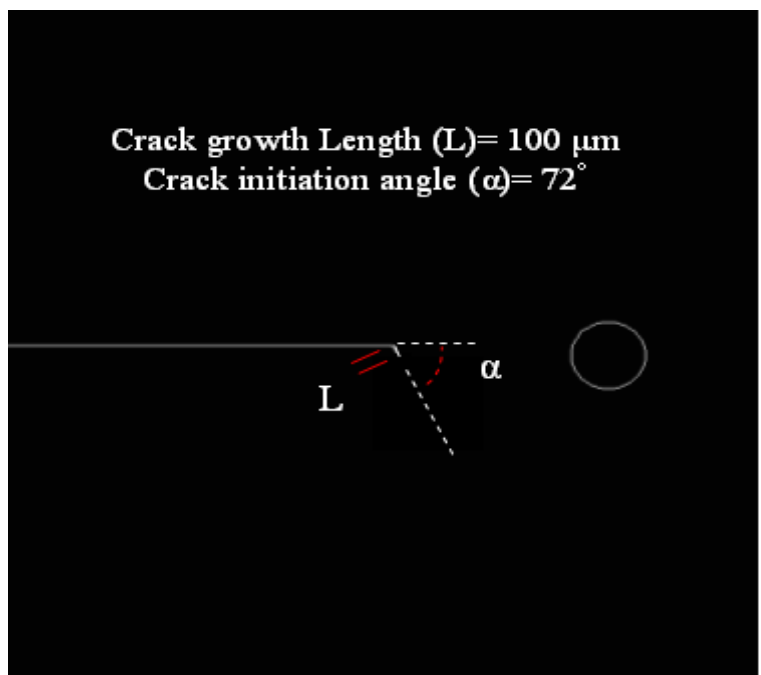

(a)

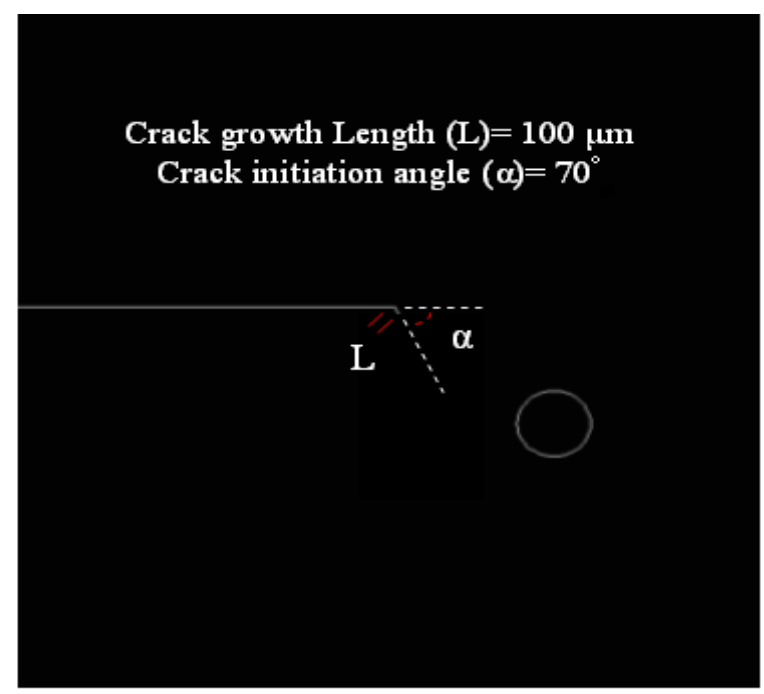

(b)

Fig. 9 Crack growth properties (b/a =25\%); a) Micro pore located at the prolongation of the crack tip; b) micro pores located diagonally below the crack tip.

From the above results it can be concluded that the worst position for a micro pore under pure shear loading is when it's situated in front of the crack tip. Because, the crack tip stress and crack growth length for linear pore configuration have the highest values in contrast with other configuration.

\section{Conclusions}

In this study the effect of presence of micro pore near a crack tip on the characteristics of crack tip plastic zone (its shape and the size) and crack growth properties, under pure shear loading, has been analyzed. The results show that:

(1)The crack growth length decreases by variation of pore situation from linear to perpendicular configuration because of decreasing in crack tip stress. In other word, its effect decrease on the crack tip stress. For linear and diagonal pore configuration, the crack initiation angle increase by pore spacing till get the standard value $\left(73^{\circ}\right)$ but for perpendicular pore configuration the crack initiation angle will be constant by pore spacing and is similar to standard.

(2)When micro pore is situated in front of the crack tip, it has the most effect on the crack growth properties so that the crack tip stress and crack growth length have the highest value in this configuration. It explains the fact that this position is the worst configuration for micro pore. It's to be note that the crack tip stress and crack growth length have the lowest value for perpendicular pore configuration.

(3)By increasing in pore spacing, the effect of pore presence disappears on the crack growth properties so that the crack growth length and crack growth angle will be equal to standard value (the values without presence of micro pore) when the ratio of b/a is about $25 \%$.

\section{Refrences}

[1]Wang, R. Q., Kemeny, J. M., 1994. A study of the coupling between mechanical loading and flow properties in tuffaceous rock. In: Nelson, P. P., Laubach, S. E. (eds), Rock mechanics: Models and measurements challenges from industry, Balkema, Rotterdam, 749-756. 
[2]Rice JR, Rosengren GF., 1968. Plane strain deformation near a crack tip in a power-law hardening material. J Mech Phys Solids; 16, 13-31.

[3]Kuang JH, Chen YC., 1997. The tip pf plastic energy applied to ductile fracture initiation under mixed mode loading. Eng Fract Mech. 58, 61-70.

[4]Rose, L.R.F., 1986. Microcrack interaction with a main crack. International Journal of Fracture 31, 233-246.

[5]Rubinstein, A.A., 1986. Macrocrack-microdefect interaction. ASME Journal of Applied Mechanics 53, 505-510.

[6]Horii, H. and Nemat-Nasser, S., 1987. Interacting microcrack near the tips in the process zone of a macro crack. Journal of the Mechanics and Physics and Structures. 35, 601-629.

[7]Grenon M, Hadjigeorgiou J, 2008 A design methodology for rock slopes susceptible to wedge failure using fracture system modeling. Eng Geol 96:78-93

[8]Gischig V, Amann F, Moore JR et al, 2011 Composite rock slope kinematics at the current Randa instability, Switzerland, based on remote sensing and numerical modeling. Eng Geol 118:37-53.

[9] Haeri, H., 2015a, Influence of the inclined edge notches on the shear-fracture behavior in edgenotched beam specimens, Computers and Concrete , 16: 605-623,

[10] Haeri, H., 2015b, Experimental crack analysis of rock-like CSCBD specimens using a higher order DDM, Computers and Concrete, 16:881-896.

[11] Haeri, H., Sarfarazi, V., 2016a, The effect of micro pore on the characteristics of crack tip plastic zone in concrete, Computers and Concrete, 17(1); 107-12.

[12]Haeri, H., Marji, M.F, 2016b, Simulating the crack propagation and cracks coalescence underneath TBM disc cutters, Arabian Journal of Geosciences, DOI:10.1007/s12517-015-2137-4

[13]Gao ,Y., Wu, D., Zhang, F. Lei, G.H. Qin H. and Qiu, Y. 2016 Limit analysis of 3D rock slope stability with non-linear failure criterion, Geomechanics and Engineering, An Int'l' Journal, 10: 5976

[14]FRANC2D/L vesion 1.5, user Guide, Cornell University; 1998.

[15]Newman JC, Jr. Dawicke DS, Bigelow CA., 1992. Finite-element analyses and fracture simulation in thin-sheet aluminum alloy, NASA TM 107662.

[16]Anderson, T.L., 1995. Fracture Mechanics: Fundamentals and Applications. CRC Press, Boca Raton, U.S.A. 688 pp. 